\title{
Online dictionaries of English
}

\author{
Robert Lew \\ Adam Mickiewicz University
}

\begin{abstract}
In this paper I present an overview of the spectrum of available online English language dictionaries, and then offer some general comments on a few selected key issues. Given the current explosion of web content, it is quite pointless to try to list every single dictionary available. It makes better sense to identify the salient categories of online dictionaries and selectively focus on their prominent and typical representatives. The first notable category, so important to the many learners of English worldwide, are the famous British monolingual learners' dictionaries (the Big Five). Here, it is interesting to observe the gradual transition to the online medium in what has sometimes been called the freemium approach. Quality general English dictionaries aimed at the native speaker are not so well represented, but there are a wide choice of specialized (subject) dictionaries of varying quality and provenance. Specialpurpose dictionaries include pronouncing dictionaries and onomasiological dictionaries. Diachronic dictionaries have also established a presence on the internet. As one guise of the Web 2.0 experience, we witness the emergence of bottom-up (or user-involvement) lexicography, with such prominent exemplars as the Urban Dictionary or Wiktionary. Hyperlinking is a fundamental feature of the web, but it is, arguably, overused in the so called dictionary aggregators: dictionary portals which put together entries from several online dictionaries. This creates highly redundant assemblages of lexicographic data. How to tap the richness of the Web but present the results in a user-friendly manner without laborious human intervention is a tough question. Another issue that still awaits satisfactory answers is the organization of access to data in online dictionaries. Even in highly respected dictionaries, there remain basic problems of access, such as with locating multi-word units, notwithstanding the upbeat tone of metalexicographers who often just pronounce the problem as essentially solved in the electronic medium. Other issues related to new technologies are the use of graphics, multimedia and alternative presentation modes, and these receive some attention. Finally, I play with the idea of the dictionary as an advanced query system sitting on top of a text corpus. Using collocation dictionaries as an example, I demonstrate that the difference between a sophisticated corpus query system and a more traditional lexicographic product may soon become something of a technical subtlety.
\end{abstract}

\section{Introductory}

The present paper is intended as an overview of online dictionaries of English, often seen, and probably rightly, as the leading lexicographic tradition of the present. Although a balanced overview is my primary goal, I will also touch upon some general issues and adopt a more evaluative position here and there. However, this will only be a secondary perspective, as the specific issues are covered in greater depth in some of the other papers in the present volume.

Obviously, given the sheer number of the currently available on-line dictionaries, no-one can hope to produce a complete catalogue, and this is not the purpose here. Rather, the idea is to present prominent and representative exemplars of specific types of dictionaries and focus on their properties of interest. But what are those types of dictionaries? As dictionaries can be, and have been, compared on a number of different levels, classifying them has traditionally 
been problematic. This has become even more of a challenge in the age of electronic dictionaries. What, then, could be the basic classifying criteria for online dictionaries?

Clearly, most of the traditional criteria can still be applied to online products. Here, of course, we find the complex (and at times confusing) network of overlapping oppositions: general/specialized subject, general/special purpose, L1/L2/FL speaker, expert/layman, contemporary/historical, etc...

There do appear, however to be some criteria or oppositions that have not been inherited from printed dictionaries but rather are specific to online dictionaries.

\section{Some additional criteria for classifying online dictionaries}

\subsection{Institutional vs. collective}

A variety of overlapping classification criteria have been used to categorize online dictionaries. For example, in terms of user involvement, there is the institutional versus collective opposition (Fuertes-Olivera 2009); the latter category signifies a collaborative effort by a community of non-professionals, who can themselves be dictionary users; an earlier paper by Carr (1997) has also used the terms bottom-up and collaborative. User-involvement is yet another designation for a similar concept, while open stresses a slightly different aspect of what might again be a fairly similar formula.

\subsection{Free vs. paid}

Collective dictionaries would normally be free to use. Conversely, institutional dictionaries need not necessarily involve fee-based access, so the free versus paid contrast is an independent one. It is also increasingly difficult to demarcate clearly between free and paid, with the clear cases leaving a substantial grey area in the middle, as revenue to the publisher can take different forms. For example, individual pay-per-view or subscription-based access is a clear case, but when syndicated as part of a more comprehensive service and sold, say, to libraries, the end user often does not bear the direct cost. Then there are cases where online access is offered (perhaps for a limited time) as a bonus for buyers of paper editions. Still closer to the free end of the cline are ad-supported dictionaries, and this appears to be a rather popular model at the moment.

\subsection{Number of dictionaries}

In terms of how many dictionaries are offered by the specific services, at least the following four options come to mind:

1. individual dictionaries: just like the traditional printed dictionaries, there are standalone, single online dictionaries;

2. dictionary sets consisting of clusters of related dictionaries may be offered from a single landing page; a good example is the Cambridge dictionaries online page ${ }^{1}$

3. dictionary portals only include hyperlinks to actual dictionaries (examples will be presented below);

4. dictionary aggregators excel at pasting together the content of various dictionaries and serving them on a single page (again, examples will be discussed below).

In my overview below, I will begin with some notable representatives of institutional dictionaries offered free of charge to the world internet community. 


\section{Institutional Dictionaries}

\subsection{General English Dictionaries}

General English Dictionaries are traditional general-purpose dictionaries which provide a relatively rich microstructural treatment of (primarily) contemporary English, which is traditionally expected from general reference desk dictionaries, and where the word list is not restricted by domain or register.

\subsubsection{American}

Traditional US dictionary publishers seem to have embraced the web: as many as three of the major American players on the market of general desk and college dictionaries make their dictionaries available online free of charge. These are the Merriam-Webster Online Dictionary, American Heritage Dictionary and Random House Unabridged Dictionary, the last one being included only as part of the Dictionary.com service (on which see 3.1 below).

\subsubsection{British}

Until recently, the available offer of online general-purpose dictionaries on the British scene had been less complete, with the traditional and most prestigious publishers (notably Oxford University Press) apparently hesitant about placing their products online for free. Only very recently, OUP created the new oxforddictionaries. com $^{2}$ lexicographic portal, built around two of the publisher's recent dictionaries: the newest (third) edition of the Oxford Dictionary of English (under the heading World English), and its American counterpart, the New Oxford American Dictionary, also in its third edition. A premium subscription service is available, with one year free for buyers of the printed copy.

The availability of the free/premium combination for these Oxford dictionaries exemplifies rather well the new business model that is currently being followed by a number of publishers: the model known by the linguistic blend freemium. The approach works on the principle that basic content and functionality is offered essentially free of charge (in response, we might say, to the free-lunch mindset of today's netizens). The free offer, however, is used as an opportunity to market and sell extra content, which might be richer lexicographic data and/or non-lexicographic content, such as exercises or language testing materials. To continue with our example, the premium oxforddictionaries.com service offers the following extra features (Judy Pearsall, personal communication):

- sense-linked thesaurus of 600,000 synonyms and antonyms;

- advanced search and browse features;

- 1.9 million sense-linked examples from the Oxford English Corpus;

- audio pronunciations;

- My Oxford Dictionary personalization features;

- browsing and search by subject area, meaning category, part of speech, etc.;

- four additional zones fully linked to dictionary content, including Writing Skills zone, Writers and Editors zone, Example sentences zone, and Puzzles zone.

To some extent, free online versions may drive the sales of paper copies - but of course this argument could be reversed, with online access deterring some potential buyers from purchasing a printed copy.

Apart from the two Oxford dictionaries, there are also other notable British dictionaries offered free of charge. Collins offers what it refers to as the Collins English Free Dictionary. ${ }^{3}$ A closer examination reveals that this is not the same as the authoritative Collins English 
Dictionary; the latter, however, does seem to be available, but only as part of TheFreeDictionary service (on which see 3.1 below). The venerable Scottish publisher Chambers offers on its website its Chambers $21^{\text {st }}$ Century Dictionary. ${ }^{4}$ Again, though not really the same as the renowned Chambers English Dictionary, the $21^{\text {st }}$ Century is still a usable, solid reference work for general consultation.

The Encarta World English Dictionary, ${ }^{5}$ having originated in a cooperation between the London-based Bloomsbury publisher and Microsoft, actually comes in two versions, and both are available via the same website; there is the World English version, marketed as the dictionary that provides unrivalled treatment of the regional varieties of English, and the localized US version; the site provides an option to switch quickly between the two, and it is fascinating to observe, by switching back and forth, the differences in the coverage of regional terms and meaning, spelling and pronunciation.

\subsection{Learners' dictionaries: the Big Five}

According to data from internetworldstats, ${ }^{6}$ English is the foreign language of some $86 \%$ of Europe's active internet users. Now, given that English is today's de facto lingua franca and that WWW content in English dwarfs out that in any other language, it becomes clear that non-native speakers are a significant category of online dictionary users, present or future. In this context, the category of English learners' dictionaries comes to the focus, since these are the reference works designed specifically with the non-native speaker in mind. English learners' dictionaries enjoy a long-standing tradition, which goes back to around the 1940's or, as some claim, the 1930's (cf. Cowie 1999). Their content has been meticulously reworked over numerous successive editions, and because of the worldwide customer base and the corresponding sales volumes, publishers of monolingual English learners' dictionaries have been able to take advantage of select teams of expert lexicographers. These dictionaries have enjoyed high levels of prestige, and so have their traditionally British publishers.

The last few years has seen free versions of British monolingual dictionaries for advanced learners appear online, one by one. On the whole, the major British MLD's have followed a pattern of remarkable similarity (Yamada 2010), perhaps as part of the competitive drive, and this is also reflected in the features offered in their online versions. There is also a more down-to-earth reason for the similarities found in a number of British MLD's: they tend to use the same software dictionary production platform from IDM.

The range of available English MLD's opens with the pioneer in this segment, Oxford Advanced Learner's Dictionary, ${ }^{7}$ a free version now roughly based on the 7 th print edition. A long-time competitor, Longman Dictionary of Contemporary English, currently in its fifth edition, has also offered a free online version ${ }^{8}$ for some time. The dictionary's landing page specifically mentions a limitation of the free version: recordings of spoken pronunciation are only available for a subset of headwords and example sentences (more specifically, the audio is available for the entries in the letter stretches D and $\mathrm{S}$ ). The note further states that audio recordings for all entries are available in "the CD-ROM version": this is not quite accurate, as the optical disk version is actually offered on a DVD-ROM. But the free version is not the only online version of this dictionary: there is also a radically different premium online edition $^{9}$, which offers essentially the same content as the off-line DVD-ROM version.

Cambridge Dictionaries Online ${ }^{10}$ represents an example of an institutional dictionary set (as defined in 1.3 above): apart from the flagship Cambridge Advanced Learner's Dictionary, four other learners' dictionaries from the publisher are available at the same address. 
Amongst the major British learners' dictionaries, Macmillan English Dictionary may well be the one to have offered the most complete set of lexicographic content online ${ }^{11}$ free of charge, including audio pronunciations of all headwords and a sense-linked thesaurus.

The one member of the Big Five set which has remained apparently sceptical when it comes to offering free online access of any kind is COBUILD. Although it has offered subscriptionbased access for some time, ${ }^{12}$ none of this is available freely, if we disregard an outdated $4^{\text {th }}$ edition being hosted on a third-party service. ${ }^{13}$ Recently, it looked as if COBUILD was set to become the most widely used learner's dictionary when, in autumn 2009, Google apparently obtained a licence for COBUILD content and placed it online as the main Google dictionary for English. This was a questionable choice, as COBUILD is not really well-suited for the type of uses that Google users were most likely to need the dictionary for, i.e. problems with text reception: of all the major learners' dictionaries, COBUILD has the smallest coverage (Rundell 2006). On the other hand, the features supporting text production would remain underused. Google's half-hearted implementation of the interface certainly would not have made users more sympathetic towards the dictionary. For example, Google dictionary included COBUILD's syntactic codes, but without a word of explanation anywhere. Surely, it is a long shot to assume that a casual user of the Google dictionary will appreciate the significance of a code such as "NVAR" (in this case, an indication that a noun in the sense so marked has both mass and individuated uses). Considering all this, it is not at all surprising that in August 2010, COBUILD was replaced as the database for Google dictionary with The Oxford American College Dictionary (Judy Pearsall, personal information).

\subsubsection{American learners' dictionaries}

Although it is the British publishers that lead the market of monolingual English learners' dictionaries, such dictionaries have also been published elsewhere, and one particular dictionary that made a premiere recently with quite a bit of publicity is the Merriam-Webster's Learner's Dictionary. ${ }^{14}$ What is rather unique about this dictionary is that the launch of its online version coincided with the publication of the first paper edition. The free online content includes audio pronunciation, and the user interface is at least as good as those of the British dictionaries, but despite the marketing claims, the lexicographic content itself is not groundbreaking, and still lacks a number of modern features now taken for granted in the leading British products (Bogaards 2010; Hanks 2009). The dictionary does have more examples than the competition, but their quality has been questioned (Hanks 2009).

Despite what some might be led to believe, the Merriam-Webster's Learner's Dictionary is by no means the first American dictionary of its type: several have already been published, and at least one of them, Heinle's Newbury House Dictionary of American English, ${ }^{15}$ is freely available online. However, the latter is a rather small dictionary and not a particularly impressive one. All in all, learners of American English may actually be better off using British-published dictionaries of American English, such as the Cambridge Dictionary of American English. ${ }^{16}$

\subsubsection{Louvain EAP Dictionary (LEAD)}

Apart from the established publishers, some academic centres are also trying to enter the field of learners' dictionaries. One particularly promising project currently in progress (not yet publicly accessible) is the Louvain EAP dictionary (LEAD), which is being developed as a dictionary for non-native writers. Its main novelty is that it is customizable in terms of field domain (business, medicine) and mother tongue (French, Dutch). In consequence, usage notes and equivalents match the $\mathrm{L} 1$ of the user, and some of the examples are domain-specific. The 
dictionary will also have (as you might expect from a product created at the Centre for English Corpus Linguistics) a solid grounding in corpora, and integrated corpus access.

\subsection{User-involvement (bottom-up) lexicography}

In the democratic world of the internet, users can play lexicographer as well and create their own online dictionaries. There is quite an impressive range of these, but let us have a look at three representative exemplars:

\subsubsection{Urban dictionary}

A success story in its own right, the Urban dictionary ${ }^{17}$ is a true bottom-up initiative which recently celebrated its 10th anniversary. One of the community features exemplified here is that users vote on the „,best” definitions. But such democracy does not necessarily serve lexicography well: as it turns out, the most liked definitions are not of the type that would really help someone who does not already know the meaning. Clearly, true explanatory definitions are too predictable and thus not "interesting" enough, and are being pushed back to the bottom of the list. Instead, collaborative dictionary entries, unless properly moderated, tend to become the playing ground for showing off wit, marking in-group membership and venting prejudice. For example, one entry at the headword BOOTYISM runs as follows: "The gospel according to Beyonce. Often confused with Buddhism." This entry is written in an abbreviated style posing as lexicographese, and manages to allude rather cleverly to the semantics as well as origins of the slang term, but it would probably not be of much help to a user who has no clue about the meaning. In this case, the author seems to be aware of this deficiency, and makes up for it in the (entirely invented) example exchange:

Todd: I'm thinking about converting to Bootyism.

Michael: Nah man, it's BUDDHISM.

Todd: No, cause in Bootyism all you do is worship ass.

\subsubsection{Wiktionary}

Wiktionary ${ }^{18}$ may be the ultimate collaborative dictionary. A recent in-depth analysis of this resource (Fuertes-Olivera 2009) presents a number of interesting findings. It is observed that, contrary to what is often claimed, Wiktionary is not a multilingual dictionary but an English dictionary with a translation overlay for several other languages. It is also noted that very similar items may receive radically different treatments, lacking internal consistency and contradicting the Wiktionary guidelines.

\subsubsection{Wordnik}

Wordnik $^{19}$ presents an interesting blend of online dictionary genres, involving a collaborative community-driven component built around a "professional" core. According to the founder Erin McKean (personal communication), user-generated content is encouraged here but in "guided" ways, with less emphasis on user-created definitions than is usual in collaborative projects. Wordnik embeds content from other datasets: at this time, Twitter and Flickr are being tapped for real-time citations and relevant images, respectively. The service employs modern data mining techniques to identify in corpora citations of the self-defining and exemplar types (McKean, personal communication). Overall, there is less reliance on traditional definitions and the emphasis is shifted to citations.

\subsubsection{Collaborative-institutional dictionaries}

Commercial publishers also try to get their users actively interested and involved in lexicography, perhaps in an effort to persuade them to stay on the site and come back for 
more. Examples of collaborative sections hosted on institutional dictionary sites suggest that the opposition institutional versus collective dictionary (Fuertes-Olivera 2009) may no longer be a sharp one. Two such examples from well-known institutional publishers are the Merriam-Webster Open Dictionary ${ }^{20}$ and Macmillan Open Dictionary. ${ }^{21}$ A perusal of the user-added entries reveals that most of the entries added would not meet the criteria for inclusion in the regular edition of the dictionary, and their presence merely provides evidence of the conventional wisdom that "the dictionary" is a collection of "all the words" of a language.

Apart from adding open dictionary components, online dictionaries sometimes offer other extras aimed at involving the users. Recent add-ons include social networking features, such as the award-winning Macmillan Dictionary blog. ${ }^{22}$

So far we have discussed general dictionaries of contemporary English, aimed at both native speakers of English and foreign learners. Let us now move beyond these common types, to diachronic and specialized dictionaries.

\subsection{Diachronic (historical) dictionaries}

Users of diachronic dictionaries are most typically language scholars, and so their level of sophistication and language awareness is normally far beyond that of lay users. As language experts, they can reasonably be trusted to make choices that a non-expert user will not be in a position to make, such as the explicit selection of microstructural data categories (and we will revisit the issue of customization in a later part of this article). The makers of academic diachronic dictionaries appear to be aware of these ramifications, as exemplified by the online version of what is perhaps the most famous dictionary world-wide (at least for English), the Oxford English Dictionary. Access to the OED is subscription-based, and affiliated scholars would most of the time rely on their institutional subscription rather than a personal one. In contrast, a more restricted (in terms of period) but no less voluminous Middle English Dictionary ${ }^{23}$ has been freely available online since 2007, when the University of Michigan completed the digitization process with the help of a government grant. The dictionary offers a rather large number of technically complex search options but these should be manageable for language scholars and their students.

\subsection{Subject field dictionaries}

There are countless online specialized dictionaries out there on the web, most of them fairly small in size, dealing with the vocabulary of a specific subject field (as well as narrower subfields). Because of the sheer number, many users will find it useful to consult online directories of such dictionaries, one of the most comprehensive being Glossarist.com: an example of a dictionary portal as listed in my provisional taxonomy under 1.3 above. Indexing portals of this type only include links to dictionaries on external pages, without themselves hosting or displaying actual lexicographic content.

The lexicographic wisdom that content and presentation are largely two separate aspects is strengthened by those products where there is a sharp contrast in quality between one and the other. One case in point is Dorland's Medical Dictionary ${ }^{24}$ from the respectable pair Merck Medicus and Elsevier, where solid content is marred by the uninspired (to say the least) access interface. Users are presented with a long chain of alphabetic stretches which have to be navigated linearly in a fashion resembling page-turning, only much slower (although there is a term search window, it does not apply to the dictionary itself, but to other services). To metalexicographers, this dictionary serves as a warning against sweeping generalizations about electronic dictionaries being faster and superior in terms of access: apparently, it is 
perfectly possible to produce an online dictionary where access is more cumbersome than in a paper book.

\subsection{Dictionaries with restricted macrostructure}

One way to think of special-purpose dictionaries is that they often involve systematically restricted treatment in either macrostructure or microstructure. In the earlier case, only a distinct subset of the vocabulary is included in the wordlist. Field dictionaries, already covered in 2.5 above, may be included here. Another exemplar of a restricted macrostructure dictionary is the well-known and successful Acronym Finder ${ }^{25}$, which aims to include acronyms, including those pronounced as one word and letter by letter (sometimes called initialisms). Although Acronym Finder does not limit its headword list to English acronyms, it is a fact that English very clearly dominates.

\subsection{Dictionaries with restricted microstructure}

In contrast to dictionaries with restricted macrostructure, restricted-microstructure dictionaries are characterized by a systematic reduction, not in the word list itself, but in the lexicographic data categories presented at each entry, compared to a general dictionary. The free Online Etymology Dictionary ${ }^{26}$ is a representative of the genre: the lexicographic data for a given headword is restricted to an explanation of the word's origins.

Pronouncing dictionaries are another major category of restricted-microstructure dictionaries, where the chief lexicographic data given indicates the phonetic form of the entry word. Semantic information is only given in exceptional cases, such as to disambiguate between graphemically identical words that are pronounced differently (i.e. homographs that are not homophones). There is the question of the exact form in which information on pronunciation is conveyed. In printed books, transcription (in one of a number of standards, the most universal being the IPA) used to be the only option, but in the multimedia environment of the web, the expectation of users is to be able to hear an audio rendition of an item's pronunciation. This expectation is met by the popular free online talking English dictionary howjsay.com, ${ }^{27}$ which provides recorded audio clips, but no written transcription. At the other end of the cline are academic pronouncing dictionaries such as the Carnegie Mellon University Pronouncing Dictionary, ${ }^{28}$ which presents transcriptions in the ARPAbet respelling system, or Péter Szigetvári's English Pronouncing Dictionary, ${ }^{29}$ which employs a variant of the SAMPA respelling system.

There is no denying that being able to hear what the word or phrase sounds like is an asset, but does this mean, as most people seem to assume, that phonetic transcription is now dispensable? It probably is for native speakers of English, but hardly so for speakers of other languages looking up English pronunciation. For them, it is an illusion to believe that just hearing a word pronounced in a foreign language is enough to register, less still learn, its correct pronunciation. Due to the effect known as categorical perception, speakers of a language tend to hear foreign language sounds through the filter of their native language phonology. Consequently, what foreigners will hear is mostly their native language sounds and tend to miss the distinctions not present in their own language. For example, a speaker of Polish may easily miss the difference between met and mat. The important advantage of phonemic transcription is that it provides an explicit graphic representation of the phonemes involved, drawing attention to the phonemes as entities. (This is not to say that the two academic dictionaries cited above do this in a very user-friendly way: they do not.) Of course, it is also true that efficient use of phonetic transcription does not usually come naturally for a language learner and requires guided training. 
But that is not the end of the story. Apart from pure phonemic identity, there is the important subphonemic phonetic detail, including positional allophony which, again, is very hard to hear for the untrained learner. Although traditional printed pronouncing dictionaries tend not to give subphonemic detail, there is no principled reason why future online dictionaries should not be able to offer a choice of the level of transcription, including a narrow-phonetic rendition for those who might want or need it. Technically, it should not be terribly difficult to take stock of at least the rule-based variants.

As noted by Sobkowiak (2009), phonetic transcription has a representational function and an indexical function. The former has to do with the representation of the phonetic form of a word (or, more generally, other linguistic string). The indexical function allows the user to use symbols for accessing (sets of) lexical items, such as when looking for words that exhibit a given phonetic pattern. A systematic transcription system is at present a prerequisite for the indexical function to be possible, although not all dictionaries that do have transcription, allow 'sound search' options. Clearly, of the three free pronouncing dictionaries here presented, Szigetvári's English Pronouncing Dictionary is the most sophisticated in this respect.

\subsection{Onomasiological dictionaries}

Onomasiological dictionaries are those that are specifically designed to take the user from a concept or idea to linguistic form, rather than explaining the meaning or use of a given form. A traditional paper dictionary of this type would most typically be a thesaurus or synonym dictionary. Thesaurus.com ${ }^{30}$ is a companion site to the popular Dictionary.com aggregator (see 3.1 below). A more interesting online example of such a dictionary is RhymeZone, ${ }^{31}$ which started off as a synonym dictionary calling itself the Semantic Rhyming Dictionary. Somewhat predictably, probably because of the phrase "rhyming dictionary" in the name, users arrived at the dictionary from search engines looking for traditional phonetic rhymes, and this is what the default search mode now offers. In fact, searching for rhyming words is also an onomasiological query, albeit in a broader sense. In the more restricted sense of onomasiological, the dictionary offers lists of synonyms, antonyms and "related words". For these, RhymeZone relies on data from the English WordNet $^{32}$ lexical database, just as so many other lexical resources do these days: it has become one of the favourite dataset for many online dictionaries, because it is free and NLP-tractable in ways that make such integration relatively easy.

One interesting way in which WordNet data is used is graphic visualization engines such as VisuWords ${ }^{33}$ or Visual Thesaurus, ${ }^{34}$ where the idea is to represent WordNet's lexical relations in a visually appealing graphical form. The latter now shows up in Cambridge Dictionaries Online entries.

Having completed a quick tour of the representative online dictionaries of English, we will move on to a number of overarching issues that are relevant and topical for online dictionaries of today and tomorrow.

\section{Some issues in online dictionaries}

\subsection{The dictionary web}

The World Wide Web is built around the concept of hypertext, where texts, documents and media make up an interconnected network. Like most other sites, online dictionaries hyperlink, interlink, embed and integrate, and it will not take long for a careful user of online dictionaries to start noticing that quite a lot of the same content crops up again and again on a 
variety of dictionary sites. For example, the very same Visual Thesaurus images which feature in Cambridge Dictionaries Online are also present at the Dictionary.com ${ }^{35}$ site. The latter is an example of a dictionary resource which does not rely on its own data, but instead aggregates lexicographic content from other electronic (online) dictionaries. Dictionary.com is a particularly popular such aggregator. The popularity, one might suspect, has a lot to do with the attractive domain name, which to many users (and search engines?) strongly suggests that this is the Dictionary (see e.g. Béjoint 2010 on the popular image of the dictionary). As of this writing, the resource aggregates lexicographic content from 15 dictionaries, including the American favourites Random House Dictionary and American Heritage Dictionary, as well as half a dozen special-purpose and special-subject dictionaries.

Another aggregator is TheFreeDictionary, with American Heritage Dictionary (again!), WordNet (again!), and Collins English Dictionary (and Thesaurus). The resource is worth consulting for this last one, as this time (compare 2.1.2 above), it is indeed the respectable Collins English Dictionary, which is generally not freely available elsewhere.

While the ability to hyperlink and embed is one that lies at the heart of the World Wide Web, in dictionary aggregators the idea is taken to extremes, with the result that such dictionary portals produce absurdly long entries by mechanically pasting together, back-toback, entries from several online dictionaries. These individual entries are often very similar, which results in highly unhelpful, many-times redundant, tortuous assemblages of disconnected lexicographic data.

\subsection{Access}

Electronic dictionaries, including online dictionaries, are often praised for their access functionality, which is claimed to be superior compared to paper book form. Clearly, the electronic interface is by definition more flexible and has a potential for efficiency that is not achievable in static printed form, but it is also true that this potential is not always properly utilized, especially if the online dictionary is retrospectively digitalized (Wiegand et al. 2010: 209). One example of a respectable online dictionary with paper-like access is the American Heritage Dictionary, which has no search facility at all, worse still is Dorland's Medical Dictionary (see 2.5 above), where outer access is even slower and more cumbersome than in a printed book. However, some online dictionaries do take advantage of the electronic media and explore alternative access routes. As an illustration of this issue, let us consider issues of access in cases where a search term potentially returns large amounts of data.

\subsubsection{The step-wise approach to outer access?}

Over ten years ago, Hulstijn and Atkins (1998) proposed what they called "step-wise access" for electronic dictionaries. In this connection, it is interesting to observe how this proposal stands up in view of the practical implementations in online English dictionaries. For this, we need to examine the volume of data that a dictionary presents to the user in those cases when a search term matches more than a single treatment unit, such as multiple lemmata (such as items of different part of speech), or includes multi-word expressions (MWE's), such as fixed phrases, idioms or phrasal verbs. The spectrum of actual solutions seen in English online dictionaries can essentially be reduced to three options:

1. a menu of target items is presented;

2. a menu is presented, but the most likely choice opens by default;

3. partial entries are listed.

The first option, by far the most common, can be illustrated using Macmillan Dictionary Online as an example. Here, a search on a word-long string team returns a vertical menu of 
nine matches, each one hyperlinked to an entry or subentry. The top of the menu looks like this:

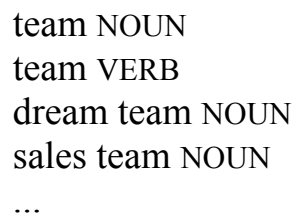

Option 2. features in the Merriam-Webster's Advanced Learner's English Dictionary, where a search for team produces a similar list of seven items, but the first of these (here again, team NOUN) is already given as the full entry immediately below the list.

Option 3. is implemented in the online dictionary at myCOBUILD.com, ${ }^{36}$ available to buyers of the printed copy of the Collins COBUILD Advanced Dictionary. The approach is an intermediate one between a bare lemma list (Option 1.) and complete entries (Option 2.). As seen in Figure 1, showing the entry TEAM in myCOBUILD.com, the dictionary interface alerts the user that multiple entries have been found, and then displays the top of each lemma with a More link leading to the complete entry for that lemma.

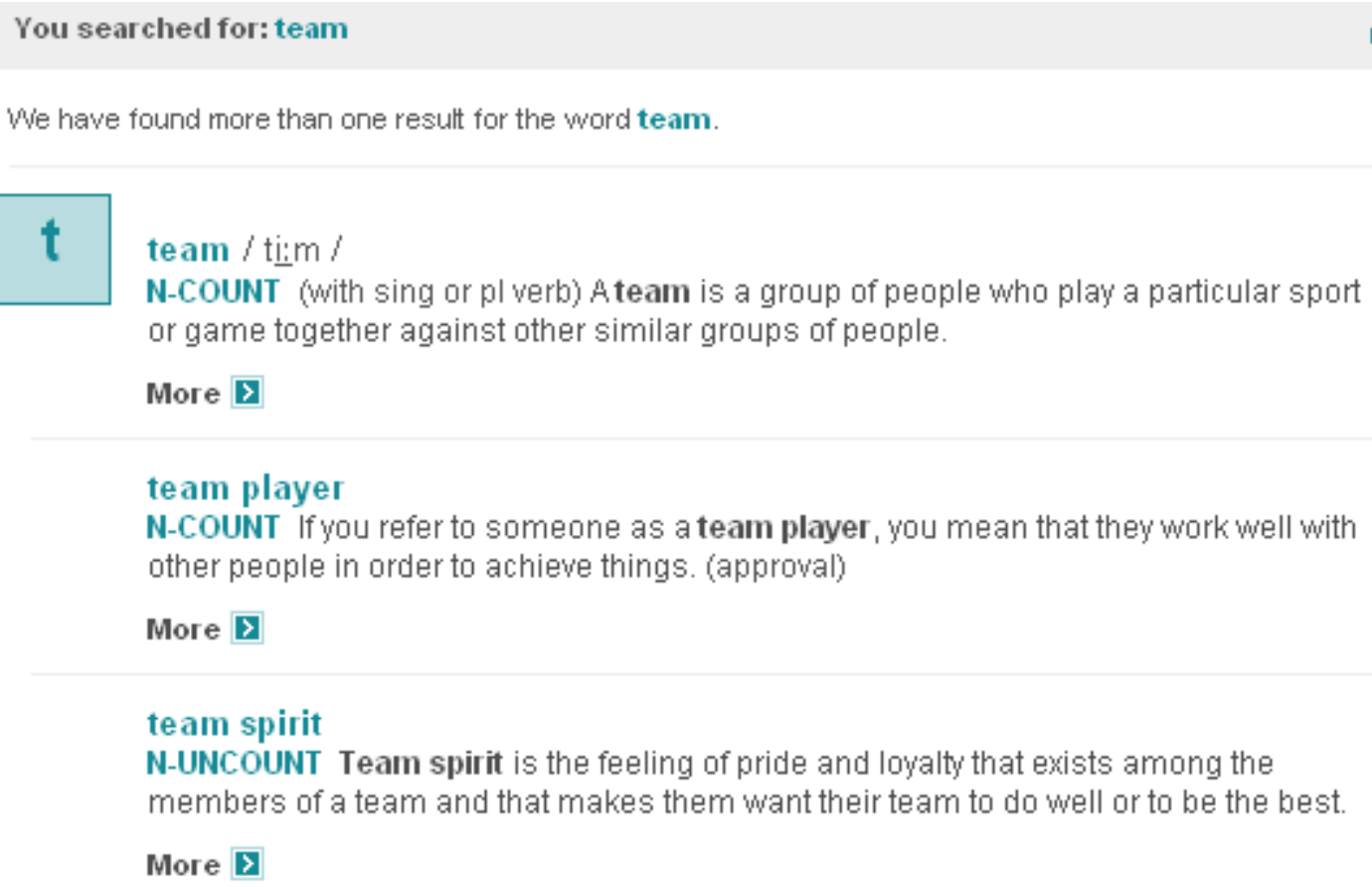

Figure 1: The entry for TEAM in myCOBUILD.com as an example of a stepwise interface

Which of the three options is best? A universal answer, ignoring lexicographically relevant details such as the nature of the lookup situation and specific user needs and skills, rarely makes sense in lexicography, but let us offer some observations that might have a more universal appeal. Option 2. looks attractive, but there is a danger here that users may fail to recognize that the default choice (as here team NOUN) is the wrong one in their case. In contrast, Option 1. seems relatively safe in terms of the risk of missing the right option, but the problem here lies in the economy of effort (aka laziness): users may lack the patience to navigate through the menu to actual full treatment, and may decide instead to ditch a tool which requires two much clicking work. In view of the above reservations, Option 3. might perhaps be optimal (other things being equal), and it is surprising that so few dictionaries have adopted it. 


\subsection{Customization and profiling in online English dictionaries}

A recent study by Tono (2011), the first dictionary use study ever to employ eye tracking, confirms the suspicion that dictionary users differ greatly in their consultation habits and strategies. The realization that different users have different needs and expectations lies behind efforts to vary or customize e-dictionaries (De Schryver 2009; Verlinde et al. 2010), and, indeed, in some online dictionaries of English we have reviewed above, users do have some ability to control the presentation of lexicographic data.

Oxford English Dictionary online has control buttons to display or hide away the following data types: Pronunciation, Spellings, Etymology, Quotations, Date Chart, Additions. It should be observed that this solution is not really lexicographic-function-driven (Tarp 2008), as the user here is required to explicitly select the data fields included in the dictionary. However, the users of an academic dictionary such as this usually represent a high level of sophistication (many being language scholars), and so they are much more likely than naive users to know directly and explicitly what data types they actually need.

Macmillan English Dictionary Online offers two pre-packaged presentation modes which can be selected by flipping the Show Less/Show More control button located next to the lemma sign. The choice is suggestive of the difference between a text reception mode and a text production mode, respectively. Switching to the more basic mode hides away the phonetic transcription, collocations (with examples), grammar labels and some of the examples.

However, synonym links are still included, even though, arguably, a synonym list is not very useful for text reception. Only a minority of dictionary users will be aware that the dictionary has a third, even simpler mode, available via the so-called interstitial page, accessible from collaborating news sites ${ }^{37}$ by double-clicking on any word in the text (luckily, the engine includes lemmatization, so the word-form stealing takes the user to the lemma STEAL). In this mode, all examples and synonyms are now absent, as one would expect in true reception mode.

User profiling is one of the highlights in the new Louvain EAP dictionary (see also 2.2.2 above), now in development, where the content presented depends on the user-selected native language and discipline (field domain) of interest.

\subsection{Multimedia in online dictionaries}

Online dictionaries can potentially include a range of multimedia content. The potential is utilized in online dictionaries of English to varying degrees.

\subsubsection{Graphics}

Graphical elements are not the sole domain of electronic dictionaries, as drawings, and (to a lesser extent) photographs, diagrams and tables have been used for a long time in paper dictionaries. However, pictorials are more easily and cheaply included in electronic dictionaries (Lew 2010). For example, illustrations are present in some entries in Cambridge Dictionaries Online or the free online version of Longman Dictionary of Contemporary English.

Thanks to the linkability of the web, it is quite possible to embed media from other providers. However, one has to count with the ramifications of limited control over hyperlinked content. For example, between (roughly) November 2009 and June 2010, the Google Dictionary used to display popular images from Google's own image search service next to some entries. As a consequence, the Google Dictionary entry for KILT included a photograph which, likely without conscious intent, conveyed all too clearly the cultural 
information that kilts need no accompanying underwear (in the interest of propriety, no screenshot is included in this article). As of this writing, the Google Dictionary has discontinued the inclusion of images.

\subsubsection{Audio}

It is becoming increasingly popular for online dictionaries of English to offer audio recordings of entry words. However, recordings of other verbal elements (definition, examples) are rarely included: of the dictionaries discussed in this article, it is only the subscription version of LDOCE which offers spoken recordings of all example sentences. One novel use of audio is to present characteristic sounds associated with the entry word: an interesting subgenre of ostensive defining. Proposals to include such elements in electronic dictionaries have been made by Dodd (1989: 91) and Ooi (1998: 112). Dodd called them sound effects, and such recordings are now available in the free Macmillan English Dictionary Online. There, the user can hear the sounds produced by musical instruments under their relevant headwords, both popular ones (GUITAR, PIANO, VIOLIN, RECORDER), as well the less well-known (SITAR). Animal noises and bird calls are likewise included (ROAR, HOOT: perhaps also worth linking under the entries LION and OWL), as well as sounds made by humans (CLAP, LAUGH, HICCUP), and noisy machines (TRAIN, HELICOPTER).

\subsubsection{Video and animation}

With the speed of the internet steadily on the increase, video content is becoming mainstream on the web. However, English online dictionaries have not really embraced the video technology so far. This caution may, in fact, be well-motivated: Chun and Plass (1996) point out that video sequences are too transient to allow the spectator to build a stable mental model. Thus, videos may not make good cognitive sense, because the viewer may be unable to pace the information processing at the rate that works for them.

Similar reservations can be raised for animated graphics, and there is at least one empirical study which appears to substantiate the pessimistic view of the effectiveness of animations, at least for dictionary-induced vocabulary learning. Lew and Doroszewska's recent study (2009) found a strong and significant negative impact of viewing animations on vocabulary retention.

\subsection{Dictionaries, corpora and lexical databases}

We have seen above repeatedly online dictionaries using WordNet data. In fact, WordNet is often loosely referred to as a "dictionary", even though, in more careful usage, it is a lexical database rather than a dictionary. I suspect that for the average user, the distinction is too fine a point. Yet, if we look at the recent history of dictionary-making, we see the growing role of information technology and structured data: corpora, databases, the use of structured markup such as XML. The current trend then is towards a clearer separation of the data layer from presentation, in line with Sue Atkins' visionary proposal (1996). Increasingly, the dictionary as the user sees it is likely to be but an epiphenomenon on a structured lexical database or corpus, and the presentation layer is set to become an automated procedure, requiring little or no human intervention (De Schryver 2009; Atkins et al. 2010; Kilgarriff and Rychlý 2010) (also see Almind and Nielsen, this volume, Gouws, this volume?).

Indeed, as corpus interfaces and wrappers get increasingly sophisticated, they can be used in some ways similar to dictionaries, so that even a more cultured user may not care what's "under the hood" as long as the interface can be used as a sort-of dictionary. As an example, consider the fully automatic collocations dictionary ForBetterEnglish.com, ${ }^{38}$ which uses the SketchEngine and GDEX technologies (Kilgarriff et al. 2008) on server-resident corpora to automatically produce entries such as the one in Figure 2. Clearly, it takes quite an expert to 
tell that this is not your usual human-made dictionary entry. The illusion would have been even better if the type-of-collocation indicators (object_of, etc.) had been given less technical and more user-friendly names.

\begin{tabular}{|c|c|c|}
\hline \multirow[t]{2}{*}{ object_of } & grit & Maddy made me laugh (with gritted teeth) to day . \\
\hline & clench : & The ones who conquer fear through repetition, through sweat, through clenched teeth. \\
\hline \multirow[t]{6}{*}{ a_modifier } & canine & The mole 's long canine teeth are sharp and pierce the hard outer skeleton of insect prey \\
\hline & molar & These tend to be the incisors in the middle of the lower jaw and the first permanent molar teeth. \\
\hline & sharp & Once upon a time it helped us avoid any large creature with sharp teeth that was making its way towards us. \\
\hline & sweet & They are all there to tempt the sweet tooth. \\
\hline & false & Mr Fellows Harrington, who lives in Ryde, is experimenting with producing aluminium dentures to replace the old style false teeth \\
\hline & deciduous : & In Scotland, for those with disease, the average was 5.0 deciduous teeth decayed, missing or filled. \\
\hline \multirow[t]{5}{*}{ modifies } & decay : & Diet Most parents know that reducing sugar in the diet is the best way to prevent tooth decay . \\
\hline & whitening & After tooth whitening in the office had lifted years of discolouration away, Mary was ready to embark on her dental rejuvenation. \\
\hline & enamel : & Tooth enamel analysis proved they could not have been brought up in the local chalk area . \\
\hline & fairy & But on second thoughts it seems a cop-out, because the same could be said of Father Christmas and tooth fairies \\
\hline & comb & Always avoid brushing curly hair, use a wide tooth comb to just separate the curls instead. \\
\hline \multirow[t]{4}{*}{ n_modifier } & incisor & This order is named due to the modifications of the incisor teeth that project forward, in a similar way to rodents. \\
\hline & wisdom : & Often there are bits of bone left in the gap where a wisdom tooth attached itself to the jawbone \\
\hline & cheek & The jaws bore small chisel like incisors, small canines, and low-crowned cheek teeth with rounded conical cusps. \\
\hline & shark : & Sharks teeth at Barton can be picked up from the foreshore making this location ideal for all the family \\
\hline \multirow[t]{2}{*}{ pp_of } & comb & Alternatively, hold the nail between the teeth of a comb. \\
\hline & gale & And no Australian has smiled as much into the teeth of an oncoming gale \\
\hline pp_with & plier & Another guard pulled out two of his upper teeth with pliers . \\
\hline
\end{tabular}

\section{Figure 2: Entry for TOотн in the ForBetterEnglish.com automated collocations dictionary}

Another corpus-based online resource, also having to do with English collocations, JustTheWord, ${ }^{39}$ is even capable of correcting unnatural word combinations. Figure 3 shows the output for the query POWERFUL TEA with the "find alternatives" option selected. The interface indicates whether the word combination is "good" (green bar on the right, colours not shown in print), or "bad" (red bar), and the length of the bar indicates the (un)typicality of the word combination. Further, the narrow blue bar directly underneath each combination indicates the degree of meaning similarity between the combination to be replaced and each candidate for replacement. Here, the collocation strong tea has the longest blue bar, and indeed this is the idiomatic phrase that a learner of English would have wanted to use instead of the non-idiomatic powerful tea, had they known any better themselves. All in all, the information provided is very useful and relevant, and it may actually be hard to believe that this output has been computed fully automatically. 
powerful tea

replacing tea in 'powerful tea'

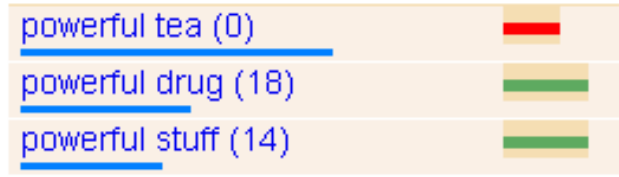

replacing powerful in 'powerful tea'

powerful tea (0)
strong tea (39)
high tea (38)

\section{powerful tea}

replacing tea in 'powerful tea', e.g. powerful drug

\section{replacing powerfu' in 'powerful} tea', e.g. strong tea

\author{
- Good Word Combinations \\ - Bad Word Combinations \\ - Similarity of meaning \\ .word - Means singular noun \\ only
}

(C) Copyright Sharp Laboratories of Europe 2005-2010.

Figure 3: JustTheWord alternative collocation suggestions for 'powerful tea'

There exist other "smart" interfaces to corpora. One of them is http://corpus.byu.edu, created and maintained by Mark Davies, and it offers free access to several corpora, including the Corpus of Contemporary American English (COCA), ${ }^{40}$ currently the largest publicly available corpus of English. Another one is the SketchEngine, ${ }^{41}$ available by subscription. A subset of the British Academic Spoken English corpus is available through IBM's many eyes ${ }^{42}$ clever visualizing interface, allowing the user to investigate the syntagmatic relationships of the most common words, though it is not all that useful for the less common combinations, due to small corpus size. A rich and comprehensive lexical database of English with a dictionary-like interface will very soon become publicly available online as part of the $D A N T E^{43}$ project.

These resources represent a high level of sophistication and so there is not much hope that their popularity will extend much beyond a relatively small group of power users; the others will just increasingly Google for any answers, irrespective of the nature of the problem, and I fear that this tendency presents a real threat to more specialized reference tools, including dictionaries.

\section{Summary and conclusion}

In our necessarily sketchy overview of English online dictionaries, we have seen that a great variety of dictionaries exist, but without proper guidance users run the risk of getting lost in the riches. It is surprising to see so many of the online dictionaries (including some from respectable publishers) still largely constrained by the paper model, with access mechanisms to lexicographic data often being substandard for today's technology. Furthermore, users may get flooded with irrelevant and highly repetitive information, especially by dictionary aggregators. And even if hyperlinking to external sources embodies the best practice in hypertext philosophy, it is not without danger, as it relinquishes much of the control over the content of "our" dictionary page. More generally, the universal use of search engines (or one dominant search engine) presents a risk of dictionaries (or any specialized online works of reference) being marginalized. Finally, learners of English are still waiting for a functiondriven lexical resource of the type represented by the excellent Base lexicale du français ${ }^{44}$ (Verlinde et al. 2010 and this volume). 


\section{Notes}

${ }^{1}$ http://dictionary.cambridge.org

${ }^{2} \mathrm{http}: / /$ oxforddictionaries.com

${ }^{3} \mathrm{http}: / / \mathrm{www}$. collinslanguage.com

${ }^{4}$ http://www.chambersharrap.co.uk/chambers/features/chref/chref.py/main

${ }^{5} \mathrm{http}$ //encarta.msn.com/encnet/features/dictionary/dictionaryhome.aspx

${ }^{6} \mathrm{http}: / /$ www.internetworldstats.com

${ }^{7} \mathrm{http} / /$ www.oup.com/elt/catalogue/teachersites/oald7/lookup?oup_jspFileName=document.jsp\&cc=pl

${ }^{8} \mathrm{http}: / / \mathrm{www}$. ldoceonline.com

${ }^{9} \mathrm{http}: / /$ ldoce.longmandictionariesonline.com/dict/SearchEntry.html

${ }^{10} \mathrm{http}: / /$ dictionary.cambridge.org

${ }^{11} \mathrm{http}: / / \mathrm{www} \cdot \mathrm{macmillandictionary.com}$

$12 \mathrm{http}: / /$ www.mycobuild.com

${ }^{13} \mathrm{http}: / /$ dictionary.reverso.net/english-cobuild

${ }^{14} \mathrm{http}: / / \mathrm{www}$.learnersdictionary.com

${ }^{15} \mathrm{http}: / /$ nhd.heinle.com/home.aspx

${ }^{16} \mathrm{http}: / /$ dictionary.cambridge.org/Default.asp?dict=A

${ }^{17} \mathrm{http}: / /$ www.urbandictionary.com

${ }^{18} \mathrm{http} / / / \mathrm{en} . w i k t i o n a r y . o r g$

${ }^{19} \mathrm{http}: / /$ www.wordnik.com

${ }^{20} \mathrm{http}: / / \mathrm{www} 3$. merriam-webster.com/opendictionary/

${ }^{21} \mathrm{http}: / / \mathrm{www} . \mathrm{macmillandictionary} . c o m / o p e n-d i c t i o n a r y /$ latestEntries.htm

${ }^{22} \mathrm{http}: / /$ www.macmillandictionaryblog.com, winner of the 2009 Edublog award for best education blog on the web

${ }^{23} \mathrm{http}: / /$ quod.lib.umich.edu/m/med

${ }^{24} \mathrm{http} / / /$ www.merckmedicus.com/pp/us/hcp/thcp_dorlands_content_split.jsp?pg=/ppdocs/us/common/dorlands/ drlnd/misc/dmd-a-b-000.htm

${ }^{25} \mathrm{http}: / / \mathrm{www}$.acronymfinder.com

${ }^{26} \mathrm{http}: / / \mathrm{www}$. etymonline.com

${ }^{27} \mathrm{http}: / /$ www.howjsay.com, the domain name being an eye-dialect rendition of the casual pronunciation of the phrase 'how do you say?'

${ }^{28} \mathrm{http}: / /$ www.cmu.edu

${ }^{29} \mathrm{http}: / /$ seas3.elte.hu/epd.html

${ }^{30} \mathrm{http}: / /$ thesaurus.com/?regHome=true

${ }^{31} \mathrm{http}: / /$ www.rhymezone.com

$32 \mathrm{http}: / /$ wordnetweb.princeton.edu

${ }^{33} \mathrm{http}: / /$ www.visuwords.com

${ }^{34} \mathrm{http}: / /$ www.visualthesaurus.com

${ }^{35} \mathrm{http}: / /$ dictionary.reference.com

${ }^{36} \mathrm{http}: / /$ www.myCobuild.com

${ }^{37}$ One example is http://www.shanghaidaily.com

${ }^{38} \mathrm{http}$ ://forbetterenglish.com

${ }^{39} \mathrm{http}: / / 193.133 .140 .102 /$ justTheWord, Sharp Laboratories

${ }^{40} \mathrm{http}$ ://www.americancorpus.org

${ }^{41} \mathrm{http}: / /$ www.sketchengine.co.uk

${ }^{42} \mathrm{http}: / /$ manyeyes.alphaworks.ibm.com/manyeyes/visualizations/3e335458358611 de909d000255111976

${ }^{43} \mathrm{http}: / / \mathrm{www}$.webdante.com

${ }^{44} \mathrm{http}: / /$ ilt.kuleuven.be/blf

\section{References}

Atkins, Beryl T. Sue. 1996. 'Bilingual Dictionaries - Past, Present and Future' in Gellerstam, Martin, Jerker Jarborg, Sven-Göran Malmgren, Kerstin Noren, Lena Rogström and Catarina Röjder Papmehl (eds.), EURALEX'96 Proceedings. Göteborg: Department of Swedish, Göteborg University, 515-546.

Atkins, Beryl T. Sue, Adam Kilgarriff and Michael Rundell. 2010. 'Database of Analysed Texts of English (Dante): The Neid Database Project' in Dykstra, Anne and Tanneke 
Schoonheim (eds.), Proceedings of the XIV Euralex International Congress. Ljouwert: Afûk, 549-556.

Béjoint, Henri. 2010. The Lexicography of English. From Origins to Present. Oxford: Oxford University Press.

Bogaards, Paul. 2010. 'The Evolution of Learners' Dictionaries and Merriam-Webster's Advanced Learner's English Dictionary' in Kernerman, Ilan and Paul Bogaards (eds.), English Learners' Dictionaries at the DSNA 2009. Tel Aviv: K Dictionaries, 11-27.

Carr, Michael. 1997. 'Internet Dictionaries and Lexicography.' International Journal of Lexicography 10.3: 209-230.

Chun, Dorothy M. and Jan L. Plass. 1996. 'Effects of Multimedia Annotations on Vocabulary Acquisition.’ Modern Language Journal 80.2: 183-198.

Cowie, Anthony Paul. 1999. English Dictionaries for Foreign Learners: A History. Oxford: Clarendon Press.

De Schryver, Gilles-Maurice. 2009. 'State-of-the-Art Software to Support Intelligent Lexicography' in Zhu, R. (ed.), Proceedings of the International Seminar on Kangxi Dictionary \& Lexicology. Beijing: Beijing Normal University, 565-580.

Dodd, W. Steven. 1989. 'Lexicomputing and the Dictionary of the Future' in James, Gregory (ed.), Lexicographers and Their Works. Exeter Linguistic Studies 14. Exeter: Exeter University Press, 83-93.

Fuertes-Olivera, Pedro A. 2009. 'The Function Theory of Lexicography and Electronic Dictionaries: Wiktionary as a Prototype of Collective Free Multiple-Language Internet Dictionary' in Bergenholtz, Henning, Sandro Nielsen and Sven Tarp (eds.), Lexicography at a Crossroads: Dictionaries and Encyclopedias Today, Lexicographical Tools Tomorrow. Linguistic Insights - Studies in Language and Communication, Vol.90. Bern: Peter Lang, 99-134.

Hanks, Patrick. 2009. 'Review of Stephen J. Perrault (Ed.). 2008. Merriam-Webster's Advanced Learner's English Dictionary.' International Journal of Lexicography 22.3: 301-315.

Hulstijn, Jan H. and Beryl T. Sue Atkins. 1998. 'Empirical Research on Dictionary Use in Foreign-Language Learning: Survey and Discussion’ in Atkins, Beryl T. Sue (ed.), Using Dictionaries. Studies of Dictionary Use by Language Learners and Translators. Lexicographica Series Maior 88. Tübingen: Niemeyer, 7-19.

Kilgarriff, Adam, Milos Husak, Katy McAdam, Michael Rundell and Pavel Rychlý. 2008. 'GDEX: Automatically Finding Good Dictionary Examples in a Corpus' in Bernal, Elisenda and Janet DeCesaris (eds.), Proceedings of the XIII EURALEX International Congress. Barcelona: Universitat Pompeu Fabra, 425-432.

Kilgarriff, Adam and Pavel Rychlý. 2010. 'Semi-Automatic Dictionary Drafting' in De Schryver, Gilles-Maurice (ed.), A Way with Words: Recent Advances in Lexical Theory and Analysis. A Festschrift for Patrick Hanks. Kampala: Menha Publishers, 299-312.

Lew, Robert. 2010. 'Multimodal Lexicography: The Representation of Meaning in Electronic Dictionaries.' Lexikos 20.

Ooi, Vincent Beng Yeow. 1998. Computer Corpus Lexicography. Edinburgh: Edinburgh University Press.

Rundell, Michael. 2006. 'More Than One Way to Skin a Cat: Why Full-Sentence Definitions Have Not Been Universally Adopted' in Corino, Elisa, Carla Marello and Cristina Onesti (eds.), Atti Del XII Congresso Di Lessicografia, Torino, 6-9 Settembre 2006. Allessandria: Edizioni dell'Orso, 323-337.

Sobkowiak, Włodzimierz. 2009. 'Review of Wells, John C., Longman Pronunciation Dictionary (3rd Edition).' International Journal of Lexicography 22.2: 191-209. 
Tarp, Sven. 2008. Lexicography in the Borderland between Knowledge and Non-Knowledge: General Lexicographical Theory with Particular Focus on Learner's Lexicography. (Lexicographica Series Maior 134.). Tübingen: Max Niemeyer Verlag.

Tono, Yukio. 2011. 'Application of Eye-Tracking in EFL Learners' Dictionary Look-up Process Research.' International Journal of Lexicography 23.1.

Verlinde, Serge, Patrick Leroyer and Jean Binon. 2010. 'Search and You Will Find. From Stand-Alone Lexicographic Tools to User Driven Task and Problem-Oriented Multifunctional Leximats.' International Journal of Lexicography 23.1: 1-17.

Wiegand, Herbert Ernst, Michael Beißwenger, Rufus H. Gouws, Matthias Kammerer, Angelika Storrer and Werner Wolski. 2010. Wörterbuch Zur Lexikographie und Wörterbuchforschung. Dictionary of Lexicography and Dictionary Research. Vol. 1 (A-C). Berlin: Walter de Gruyter.

Yamada, Shigeru. 2010. 'EFL Dictionary Evolution: Innovations and Drawbacks' in Kernerman, Ilan and Paul Bogaards (eds.), English Learners' Dictionaries at the DSNA 2009. Tel Aviv: K Dictionaries, 147-168. 